\title{
Issues and Strategies on Female Human Resources Development in China \\ Lizhi Chen ${ }^{*}$, Hui Tian
}

School of Economic and Management/Nanjing University of Science and Technology, China

*Corresponding author: Lizhi Chen, Master Degree Candidate, 526810234@qq.com

\begin{abstract}
The contempt and demeaning in evaluation of women's ability has existed for a long time, and the development and utilization of female resources is always at a low level. With the development of human civilization and education levels, not only the social status of women is improving, but also the female human resources is playing an increasingly important role in human resources. However, owing to historical heritage of traditional culture and the physiological reasons, the development of female human resources is still not optimistic. In this paper, we discuss the current situation and issues of female human resources development, and the corresponding strategies have been proposed.
\end{abstract}

Key words: female; human resource; development

\section{Introduction}

As human resources are the most initiative resource, the study of the human resources development has aroused wide attention by scholars. Although there is an old Chinese saying that women hold half the sky, the contempt and demeaning has existed for a long time in evaluation of women's ability, and the development and utilization of female resources is always at a low level. With the development of human civilization and education levels, not only the social status of women is improving, but also are the female human resources playing an increasingly important role in our human resources.

Compared to men, women employees have their unique advantages. The human resources professor Metcalfe from the University of Leeds did a community survey, which showed that women has several advantages in the professionalism compared to men: more patient, more creative, do better at cooperation, more considerate and more pragmatic. Chi et al proposed that the advantages of female human resources mainly show in following aspects: first one is physiological advantage, including the early development of language skills, auditory sensitivity, high olfactory sensitivity, strong memory, accurate and intuitive ability, wide amplitude of diffusing thinking, psychological stability, good operating coordination, patience and persistence and longer life. Second one is social culture advantage.

However, owing to historical heritage of traditional culture and the physiological reasons, the development of female human resources is still not optimistic. Especially with the release of a comprehensive two-child policy in China, for those women in the workplace who are eligible under the new rules, it is a question whether they are going to have second children or not. As for managers, the problem is how to effectively develop and manage human resources. How to effectively develop female human resources as well as protect the right of female employment, which has aroused wide concern. 


\section{Current situation of female human resources in China}

According to the sixth national census data in 2010, there are 490 million working-age female who is 15-year-old to 64-year-old, a net increase of 64.693 million more than in 2000, an increase of more than 6,635,000 compared to male. In 2010, the employment ratio of women is $61.7 \%$, and the employment ratio of 16 -year-old to 54 -year-old women is $69.9 \%$. But the employment ratio of women is $13.8 \%$ lower than male, and China's 16-year-old to 54-yearold women is constantly declining in recent two decades, which makes the gender gap further expand. According to data from the Organization for Economic Cooperation and Development (OECD), in 2014 up to 70\% of women get into the workplace, compared with South Korea and India were 55\% and 27\%, respectively. Compared with neighbouring countries, Chinese women have more job opportunities. But what is not optimistic is that the ratio of women employment has been constantly declining since 1990, and it is more difficult for women to get employed again after laid-off than men.

Female human resources development and utilization plays a very unique and irreplaceable role in sustainable development of economy and society. Huge working-age female population, not only provides sufficient human resources for economic development, but also brings challenges for the female human resources development and utilization.

\section{Issues on female human resources development in China}

\subsection{Gender discrimination during employment}

Female employment discrimination refers to a social phenomenon that the employers refuse to employ women for gender reasons. Due to historical, traditional notion and other reasons, the female employment discrimination always exists when women look for jobs. Most women in the career development process have to be faced with going through reproductive growth stage. At this stage, the employers need to provide labor protection and benefits for women, and new candidates are required to replace their places, which will undoubtedly increase the corporate employment costs. With the implementation of a comprehensive two-child policy, the cost borne by the employers will increase by several times, so that employers do not want to, even do not dare to use more female employees. As such, gender discrimination in employment brings the inequality for job opportunities at first. Then, Hou et al proposed that gender discrimination in employment will tilt the social resources to men. Here, social resources refer to the resources including the information about career, incumbency training, job promotion, the opportunity to broaden their horizon, the possibility to participate in decision-making and the usage of social network. These resources play a important role in sustained development of human resources and promoting their access to greater development.

\subsection{Lack of effective guarantees and monitoring mechanisms for female employment rights} Currently, our legislation protecting women's employment right has been basically formed "People's Republic of China Constitution" as the fundamental, including the "People's Republic of China Women Protection Law", "People's Republic of China Labor Law", "Female labor protection regulations", "People's Republic of China maternal and Child health law", "employment Promotion law" and a series of laws and regulations to guarantee women's rights. In China's relevant laws, expressly showing that women have equal rights with men in the policy, economy, society, culture and family, employers are not allowed to refuse to 
employ women or raise the employment standards for women while recruiting, and it has to be implemented in equal pay for equal work. Yang et al proposed that though female employment is an issue which government cares about, problems still remain, such as low legislative level, the lack of gender awareness in legislation mentally, fuzzy legal definition and so on. For the protection of women's labor rights, a complete set of corresponding judicial proceedings have not formed. So the relevant legal provisions' operation is difficult, guarantees and monitoring mechanisms are still lacking.

\subsection{Unreasonable and imbalanced resources structure}

Since the reforming and opening up, a large number of outstanding women have emerged in China in the fields of politics, economy, culture, education, and science and technology. But in general, the structure of female human resources is not reasonable, which mainly manifested in the industrial structure and occupational structure. According to the sixth national census data, the employment ratio of women in the primary industry was $53.22 \%$ in 2010, higher than that in the second industry, which was $19.25 \%$, and the employment ratio in the tertiary industry was $27.53 \%$. Based on relevant data analysis, Ma et al proposed that the employment ratio of women in the primary industry is always higher than that of men, indicating the character that feminization of agriculture has existed all the time. Compared to men, the distribution ratio of women in these three industries is less balanced, indicating there is still much room for optimization in the future. As for the occupational structure, "China Population and Employment Statistics Yearbook" shows that in 2012 China's women occupational structure is composed of $1.0 \%$ head of unit, $10.9 \%$ professional and technical personnel, and $4.4 \%$ official clerks. Total proportion of these three types which called "white collar" career is lower than that of men, but higher in the "blue collar", reflecting that the overall low level of female occupational status.

\subsection{Inadequate female human capital investment}

Female human capital investment is low and investment types are limited, mainly manifested in female education and cultural level. According to the sixth national census data, the higher the cultural level is, the lower proportion of women is, and the overall cultural level of women is lower than men. The data from "China Population and Employment Statistics Yearbook" shows that by the end of 2012, the employment ratio of those women who get college and higher education is just $13.55 \%$, while that of those women who are under primary education is up to $72 \%$. This shows that the vast majority of female employees still do not get rid of the dilemma of low education, low quality of employment. And the low proportion of highly education also influences women to enhance the quality of employment and professional status.

\section{Strategies on female human resources development in China}

\subsection{Establish a sense of equality between men and women, encourage female do self- development actively}

Development demand and growth motivation play an important role in development and utilization of female human resources, and female self-development is the key. Restrained by gender traditional feudal notion, when women are making educational and career choices, 
they fear for some specialties and jobs, which greatly reducing the female sense of career selfefficacy. Therefore, in order to improve the situation of female human resources development in China, women should change their traditional gender notion at first, wake up their selfdevelopment consciousness. Eliminate gender discrimination and bias against women through propaganda and education. Encourage women actively involved in socio-economic activities, eliminate the fear and set up self-confidence through practice. Arousing women's achievement motivation, competitive spirit and strong sense of social participation, this is the essence of female human resources development.

\subsection{Improve female education level, optimize and adjust female human resource structure}

To truly realize the effective development of female labor, the overall education and cultural level of female workers must be improved. Only if female workers have improved their own quality and cultural level, is it possible that more employment opportunities will be obtained, and women's own labor capacity will be developed and enhanced. To improve the overall quality and cultural level of women, government should increase investment in education, at the same time, we should pay particular attention to underage female education and the serious phenomena of girls' dropouts in rural areas. Then, we should encourage and support those adult women who are in low educational level to take continue education in order to improve the overall quality level. Furthermore, we should lay emphasis on higher education of women to increase the proportion of women in higher education level, to develop more high-level female talent to optimize female human resources structure.

\subsection{Introduce a gender perspective to the human resource development}

On the premise of gender equality, differences between male and female labor force still cannot be ignored, the development of female human resources should begin with a gender perspective. Female labor force is unique, the development program cannot be simply based on neutral or male data. When collecting and analyzing relevant data, a gender perspective should be introduced, and men and women data should be collected separately. The organization should establish female information management system to collect the number of female labor force, quality, cultural level, skill level and other indicators, so the female labor force development programs can be developed based on the information collected. In the process of implementation and results evaluation of the development program, what need to give full consideration to is that what impact it will have on men and women respectively and if there are any differences.

Female career development is also very important. With the development of social economy and enhancement of female main body awareness, female workers are more eager to achieve their social value, to maximize the success of career development. But it is noted that the career of woman has features of short life cycle and stage employment. From a gender perspective to study the career development of women, it can help women take the professional development path as well as overcome the adverse effects during career development. 


\subsection{Establish and improve female workers employment security and surveillance systems}

Government should further improve policies and legal system, gender equality awareness should be included in all levels of government decision-making, and change existing phenomenon that regulations that safeguard the rights of women is not in place as soon as possible. Local governments should increase the support and supervision for protection and maintaining of female rights. Besides, a sound system of democratic supervision should be established, so that the public can also participate in the maintenance of female labor rights to achieve a comprehensive supervision. Furthermore, many female workers are lack of awareness of rights, they do not know much about the relevant laws and regulations, so they cannot reasonably use legal weapons to safeguard their legitimate rights. Therefore, we should strengthen the propaganda of relevant legal measures to protect and safeguard the legitimate rights of women, strengthen the training of maintaining legal rights of female workers, and help more female workers to know how to maintain legal rights when their legitimate rights are infringed. In addition, we should also make vigorous propaganda for civilization, equality, progress gender culture, to actively create social and cultural environment that is conducive to the development of women.

\section{Conclusion}

With social progress and development, female human resources are playing an increasingly important role in the political, economic, educational and other aspects. China owns a huge number of female labor force, so the development and utilization of female human resources plays a very important and irreplaceable role in China's economic growth and social harmony. Female human resources development and utilization is still not very ideal, mainly manifested in four aspects: gender discrimination during female employment, lack of effective guarantees and monitoring mechanisms for female employment rights, unreasonable and imbalanced resources structure, inadequate female human capital investment. For these issues, corresponding strategies have been proposed: establish a sense of equality between men and women, encourage female actively self-development, improve female education level, optimize and adjust female human resource structure, introduce a gender perspective to the human resource development, establish and improve female workers employment security and surveillance systems.

\section{References}

1. Q. T. Zhang, Research on Moderate Achievement Motivation Promoting Female Human Resource Development, Soft Science. 2010.

2. J. Luo, Important Function of Development of Rural Female Human Resources for Promoting Modern Agricultural Development, International Conference on Education, Management and Computing Technology. 2015.

3. Q. Juling, L. Fang, Study on Human Resource Quality Promotion of Rural Female and New Countryside Construction, International Conference on E-Business and EGovernment, IEEE Computer Society. 2012.

4. Y. Li, J. Ma, Promoting Career Development of Female Managers by High Commitment Human Resource Management, Human Resources Development of China. 2014. 
5. N. Zhang, Study on the impacts of differences of human resources environment on female employment__ Tianshui City in Guansu Province as an example, Journal of Henan Institute of Science \& Technology. 2010. 